\title{
Intervenção visando a auto-estima e qualidade de vida dos policiais civis do Rio de Janeiro
}

\author{
Self-esteem and quality of life: essential for the mental health \\ of police officers
}

Edson Ribeiro Andrade ${ }^{1}$

Edinilsa Ramos de Sousa ${ }^{1}$

M aria Cecília de Souza M inayo ${ }^{1}$

${ }^{1}$ Centro Latino-Americano deEstudos deViolênciae Saúde Jorge Carelli, Escola Nacional deSaúdePública, Fiocruz. Av. Brasil 4036/700, M anguinhos. 21040-361 Rio deJaneiro RJ. edsonandrade2004 @yahoo.com.br

\begin{abstract}
The results here shown are part of an action-research that aimed to elaborate, apply and evaluate a pilot project for contributing to the mental health of Rio de Janei ro police officers. This research comprises both quantitative and qualitative approaches in an ex-ante and ex-post evaluation pattern. The subjects of this research were 148 police officers serving in a special division of the city of Rio de Janeiro Police Department ( 76 were placed in the Experimental Group and 72 in the Control Group, according to certain variables). The article focuses on the results of the assessment made through standardized scales of self- esteem (RosenbergScale), quality of life (WHOQOL-Bref), and is complemented with a qualitative assessment using Content Analysis. The results show that interventions aimed at producing emotional support for police officers with emphasis on Q uality of Life and Self-Esteem are possible and useful.
\end{abstract}

Key words Quality of life, Self-esteem, Workers' health, Police officers, Police
Resumo A presentamos partedeuma pesquisa-ação por meio da qual elaboramos, aplicamoseavaliamos uma proposta piloto de intervenção, visando a contribuir para a saúde mental de policiais civis do Rio de Janeiro. Conjugamos abordagem quantitativa e qualitativa em desenho com características de avaliação ex-ante eex-post. Participaram 148 policiais de uma delegacia especializada da capital (76 alocados no GrupoExperimental e 72 no Grupo de Controle, pareados segundo algumas variáveis). A aferição da auto-estima, feita pela escala de Rosenberg, mostrou diferenças no GE após a intervenção. Não observamos diferença na qualidade de vida, medida pelo WHOQOL-Bref. A maioria dos policiais avaliou positivamente a intervenção, sugerindo sua ampliação para a categoria como um todo. Concluímos que é possível e proveitoso realizar intervenção que ofereça suporte emocional aos policiais, enfocando autoestima e qualidade de vida.

Palavras-chave Qualidade de vida, Auto-estima, Saúde do trabalhador, Policiais civis, Polícia 
Introdução

A intranqüilidade da população brasileira quanto à segurança pública éhojeuma realidade nacional. No entanto, a questão da segurança pública é geralmente pensada tecnicamente sem levar em conta a pessoa do policial.

Foi em busca de respostas para esta questão de valorização dos policiais que, imbuídos dos conhecimentos adquiridos em outros estudos $s^{1,2}$, elaboramos uma pesquisa-ação fundamentada em conhecimentos da psicologia social, da psicologia clínica e da psicologia organizacional, propondo um tipo de intervenção fundamentado em conceitos como processo de trabalho, carga de trabalho, qualidade de vida e auto-estima.

Segundo Minayo-Gomez e Thedim-Costa ${ }^{3}$, o conceito de processo de trabalho se forma na interseção das relações sociais, técnicas e representações que configuram a produção de bens e serviços. A partir destes autores, entendemos quea análise do processo de trabalho dos policiais, isto é, a compreensão das relações entre esses trabal hadores e seu objeto de trabalho, permite identificar as mudanças necessárias para a mel horia da sua qualidade de vida e das relações no âmbito das suas atividades profissionais que juntam tecnologias, relações e representações.

De acordo com Visnikar eM esko ${ }^{4}$, todas as forças policiais do mundo estão se defrontando com as conseqüências do estresse a que seus policiais estão expostos e, diante deste quadro, é prementea busca de alternativas para minimizar o sofrimento, tendo em vista, inclusive, a eficácia de suas ações. Ao discutir acerca da organização do trabalho, De jours ${ }^{5}$ destaca que fatores como conteúdo da tare fa, divisão de trabal ho, sistema hierárquico, modalidades de comando e as relações de poder são chaves para se entender o processo saúde-doença.

0 processo de trabalho dos policiais se situa no campo dos serviços e dos serviços públicos, área na qual éainda incipientea literatura brasileira. A grande especificidade destegrupo consiste no fato de que, ao atuarem como agentes repressores da criminalidade e de garantia da ordem, os policiais convivem com a violência que se exerce sobre eles, de modo imaginado ou concretamente vivi$\mathrm{do}^{6}$. Seu trabalho implica riscos inerentes ao desempenho de suas atividades, gerando estresse e outros problemas de saúde física e mental ${ }^{1}$.

Apoiamo-nos também na noção de carga de trabalho, desenvolvida por Laurell eN oriega ${ }^{7}$, queconsideram as cargas físicas (químicas, biológicas e me cânicas) e as características fisiológicas e psíquicas.

No caso dos policiais civis, atuamos no desven- damento e redução das cargas fisiológicas e psíquicas e em relação à insalubridade do seu objeto e ambiente de trabal ho.

No âmbito do conceito de qualidade de vida, saúde e doença constituem as duas faces de uma mesma moeda. A Organização M undial de Saúde (OM S) define qualidade de vida como a percepção do indivíduo de sua posição na vida, no contexto da cultura e sistema de valores nos quais ele vive e em relação aos seus objetivos, expectativas, padrões e preocupações 8 .

M inayo, $\mathrm{H}$ artz e Buss ${ }^{9}$ ressaltam que qualidadede vida éuma representação social queseestrutura em dois parâmetros: objetivos, que dizem respeito à satisfação das necessidades básicas e criadas pelo grau de desenvolvimento econômico e social da sociedade; e subjetivos: relativos ao bemestar, felicidade, amor, prazer e realização pessoal.

Em linhas gerais, as várias definições destacam, por um lado aspectos físicos (prazer, sono e re pouso, etc.) edo meio ambiente (moradia, recreação e lazer, transporte, etc.); e, por outro, aspectos psicológicos e relacionais. N esta pesquisa, privilegiamos esses últimos.

O significado da auto-estima implica o compromisso do ser humano em conscientizar-se, responsavelmente, de suas possibilidades de escolha e, num dado momento, sentir-se livre para exercer seu poder de decisão. Ela tem como fonte características próprias da pessoa, que em determinadas situações ou momentos vivencia uma disposição íntima para exercitar as capacidades próprias de sua consciência, buscando um sentido para si e para aquilo que a cerca ${ }^{10,11}$.

Para Rosemberg ${ }^{12}$, auto-estima é uma avaliação que o indivíduo efetua e comumente mantém em relação a si mesmo, expressando uma atitude de aprovação ou desaprovação.

0 concei to de auto-estima diz respeito, segundo Bednard e Peterson ${ }^{13}$, à forma como o indivíduo el ege suas metas, aceita a si mesmo, valoriza o outro e projeta suas expectativas e projetos. Coopersmith ${ }^{14}$ ressalta que o ponto fundamental da auto-estima é 0 aspecto valorativo. 0 autoconceito pode ser considerado uma organização hierárquica e multidimensional de um conjunto de percepções de si mesmo. 0 conteúdo dessas percepções étudo aquilo queo indivíduo reconhece como fazendo parte de si. É adaptável, regulado pelo dinamismo individual, pelas características da interação social e pelo contexto situacional| ${ }^{15}$. A autoestima éuma parte do autoconceito. Expressa sentimento ou atitude de aprovação ou de repulsa de si mesmo, e até que ponto o sujeito se considera capaz, significativo, bem-sucedido evalioso. 
Como vemos, o conceito de auto-estima é semel hante para al guns dos autores citados, constituindo-se numa experiência subjetiva acessível às pessoas através de relatos verbais e comportamentos observáveis.

Tanto o autoconceito, quanto a auto-estima são atributos profundamente individuais, embora moldados nas relações cotidianas. São também decisivos na relação do indivíduo consigo mesmo e com os outros, influenciando na percepção dos acontecimentos e das pessoas, eno comportamento e nas vivências do indivíduo.

Assim, é possível destacar a condição de um grupo que carrega consigo as especificidades de "ser policial civil", conforme ressaltam Minayo e Souza': A imagem do policial civil, assim como a de qualquer categoria, é construída a partir da identidade com sua profissão e das relações mútuas que se estabel ecem entre as pessoas que ocupam este status, instituição na qual está inserido e a sociedade em geral. Esta construção éatravessada pela reflexividade. Toda pessoa antecipa as reações sociais que as suas ações podem gerar. Esta capaci dade de supor as reaçoes alheias e incluí-las num cenário de identificação conforma a própria sociabilidade e a intersubjeti vidade. Assim, todo sujeito reinterpreta as "interpretaç̃es" e opi ni ões dos outros sobre ele próprio.

N este artigo, buscamos especificamente mostrar os dados relati vos à auto-esti ma e à qualidade de vida dos policiais, a partir do citado processo de intervenção.

\section{M etodologia}

Este estudo se filia, metodologicamente, à pesquisa-ação ${ }^{16,17}$, segundo a qual determinado tipo de intervenção é acompanhado, cuidadosa e metodicamente, por uma auto-avaliação (do grupo que passa pela intervenção) e pela avaliação do próprio pesquisador. N esta investigação, elaboramos, aplicamos e avaliamos uma intervenção denominada sensibilização vivencial, cujo objetivo foi oferecer suporte emocional a policiais civis. 0 estudo conjugou abordagens de cunho qualitativo e também quantitativo em um desenho que relaciona características de avaliação ex-ante e do tipo expost $^{18}$, conforme pode ser observado na Figura 1.

Esta iniciativa envolveu todos os policiais civis de uma delegacia especializada do Rio de Janeiro, divididos em dois grupos: 76 no Grupo Experimental/GE e 72 no Grupo Controle/GC. Esses foram pareados em relação às seguintes variáveis: idade, tempo de serviço, sexo, escolaridade e funções (administrativas/internas versus trabalho de rua). A análise feita antes da intervenção mostrou que os grupos eram semelhantes.

O conjunto dos policiais, ao início do estudo, possuía as seguintes características: $93 \%$ eram do sexo masculino; $65 \%$ tinham 36 ou mais anos de idade; $64,2 \%$ seautodeclararam brancos; $50 \%$ possuíam curso superior completo e $4 \%$ tinham pósgraduação; a grande maioria estava casada ou tinha companheiro(a); 67,6\% referiram ter filhos; $42,6 \%$ entraram na instituição há até cinco anos e $36,5 \%$ está na polícia en treonzee vinteanos; $80,0 \%$ ocupavam o cargo de inspetor de polícia.

Os grupos experimental e controle eram diferentes quanto aos cargos ocupados na Polícia. No GE, na fase inicial, havia $69,7 \%$ de inspetores de polícia e 30,3\% estavam desempenhando outras funções. N o GC, os inspetores eram $91,5 \%$ e nos demais cargos estavam $8,5 \%$ desses policiais. $\mathrm{Na}$ fase final da pesquisa, os grupos estavam assim

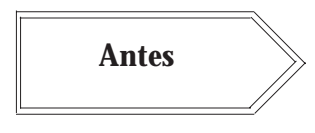

T1 / Fase 1 - Baseline

Grupos Experimental/Controle Questionários

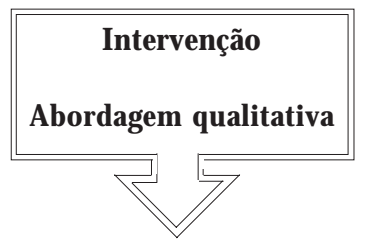

- Questionários - Oficinas

- Questionários - Final

- Grupo de debate final

- Diário de Campo

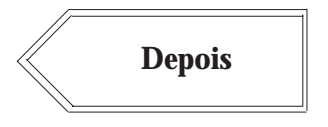

T2 / Fase 2

Grupos Experimental/Controle Questionários

Figura 1. Desenho da pesquisa. 
constituídos: no GE, 70,0\% dos policiais eram inspetores e, no GC, 91,2\% deles o eram.

A intervenção no $\mathrm{GE}$ foi considerada como treinamento do Programa Delegacia Legal, ao qual os policiais civis precisam se submeter quando passam a trabalhar nessas delegacias. O Programa Delegacia Legal, que vem sendo implantado em todas as delegacias do Estado do Rio de Janeiro, possibilitou aos policiais civis condições mais favoráveis para o exercício das suas atividades.

A delegacia de polícia em quefoi aplicada a sensibilização estava sendo transformada em Delegacia Legal na época do estudo, motivo pelo qual foi escolhida. Paralelamente, o Grupo de Controle foi submetido a treinamento com conteúdos técnicos de atividades policiais especificas oferecido pelo Grupo Executivo durante o mesmo período.

A pesquisa ea intervenção foram pactuadas com o Grupo Executivo em relação ao local onde seriam realizadas e aos temas. Para isto, foi imprescindível a autorização do delegado responsável pela delegacia selecionada. Os policiais dessa unidade foram consultados previamente, através de um questionário, sobre sua anuência para a participação no estudo. A grande maioria deles respondeu afirmativamente.

\section{Intervenção para sensibilização vivencial}

A construção da proposta de intervenção durou quatro meses. Várias reuniões foram feitas com a equipe de pesquisa ecom o Grupo Executivo para a escolha dos temas a serem trabalhados nas oficinas. Também foram feitas entrevistas com informantes-chave (dois delegados e três policiais) para identificar temas de interesse do grupo. Que atividades poderiam ser realizadas com os policiais civis da cidade do Rio de Janeiro, visando a melhorar a sua saúde mental? A partir das respostas a essa pergunta norteadora, da experiência dos pesquisadores, dos resultados de estudos e da discussão com o Grupo Executivo foram propostos temas e definidas ações em torno de três eixos (Quadro 1).

A sensibilização vivencial ocorreu efetivamente dejunho a outubro de 2005, em encontros quinzenais com duração de três horas cada, realizados na Academia de Polícia do Rio de Janeiro.

As oficinas foram conduzidas por experts (facilitadores/pesquisadores e dinamizadores/convidados), muitos dos quais com experiência anterior de trabalho com policiais. Todos foram orientados sobre a especificidade da proposta e do grupo com o qual lidariam. No Quadro 1, vemos que cada tema estava relacionado com um ou mais eixos deinteresseda pesquisa. Em algumas atividades, o GE foi abordado por inteiro. Para garantir a qualidade e efetividade da proposta, em algumas oficinas o grupo foi subdividido, ora em dois, ora em quatro grupos, objetivando maior aproximação entreos participantes edestes com os experts. Toda a operacional ização do processo constituiu um árduo trabalho de agendamento com os policiais, de preparo dos materiais (TV, vídeo, CD, datashow, instrumento musical, tatame, colchoneteefrutas), dereserva eadaptação do ambiente onde as oficinas se realizaram.

Quadro 1. Temas das oficinas e suas relações com os eixos norteadores da pesquisa.

\begin{tabular}{|l|c|c|c|}
\hline \multicolumn{1}{|c|}{} & \multicolumn{2}{c|}{ Eixos da Pesquisa } \\
\hline Temas das Oficinas & Auto-Estima & Qualidade de Vida & Cultura e Clima \\
\hline Integrando pela Alegria I & $X$ & $X$ & $X$ \\
\hline Integrando para Resgatar Sonhos & & $X$ & $X$ \\
\hline Estresse e Risco & $X$ & $X$ & \\
\hline Relaxando para "agüentar o tranco" & $X$ & $X$ & \\
\hline Polícia e Vida Familiar & $X$ & $X$ & \\
\hline A Auto-imagem do Policial & $X$ & $X$ & \\
\hline Espiritualidade & $X$ & $X$ & $X$ \\
\hline Oficina de crescimento pessoal & & $X$ & $X$ \\
\hline Integrando pela Alegria II & $X$ & $X$ & \\
\hline Peça teatral: “Navegar é Preciso” & & $X$ & \\
\hline
\end{tabular}




\section{Abordagem quantitativa}

Os policiais preencheram um questionário com questões fechadas. Essa atividade levou em torno de dois meses, durante os quais foram também analisados vários instrumentos de investigação usados por outros grupos afins que trabalharam variáveis similares ${ }^{1}$.

Após o pré-teste, a versão final do questionário constituiu-se de 76 itens, distribuídos em quatro blocos: 1) características funcionais e pessoais; 2) qualidade de vida; 3) auto-estima e 4) clima e cultura organizacional. Esse instrumento foi aplicado antes e depois de cada intervenção: 148 questionários na fase 1 e 118 questionários na fase 2 .

Além dealgumas questões elaboradas pela equipe, foram incluídas quatro escalas padronizadas: 1) WHOQOL-Bref, para avaliar a qualidade de vida; 2) Escala de Rosemberg, que afere a autoestima; 3) escala de apoio social, e 4) diagnóstico organizacional de Rosa Krausz, para avaliar clima e cultura organizacional. No presente artigo, são consideradas apenas as duas primeiras escalas.

0 World Health Organization Instrument to Evaluate Quality of Life/WHOQOL-Bref é a versão abreviada de um instrumento elaborado pela Organização Mundial de Saúde. Foi traduzido e validado para o Brasil por estudiosos da Universidade Federal do Rio Grande do Sul/UFRS' ${ }^{19}$. Sua versão em português apresentou características satisfatórias de consistência interna, validade discriminante, validade de critério, validade concorrente e fidedignidade teste reteste. Com esse instrumento, buscamos compreender as percepções subjetivas dos indivíduos sobre seu contexto cultural, social e meio ambiente.

O WHOQOL-Bref está constituído de 26 questões que abrangem quatro domínios: 1) físico (dor e desconforto; energia efadiga; sono erepouso; atividades da vida cotidiana; dependência de medicação ou de tratamentos e capacidade de trabalho); 2) psicológico (sentimentos positivos; pensar, aprender, memória e concentração; auto-estima; imagem corporal e aparência; sentimentos negativos; espiritualidade, religiosidade e crenças pessoais; 3) relações sociais (interações pessoais; suporte/apoio social; atividade sexual; e 4) meio ambiente (segurança física e proteção; ambiente no lar; re cursos financeiros; cuidados de saúdee sociais: disponibilidade e qualidade; oportunidade de adquirir novas informações e habilidades; participação deeoportunidades de recreação/lazer; ambientefísico: poluição/ruído/trânsito/clima; e transporte).

A escala de auto-estima de Rosenberg é uma medida unidimensional tipo Likert, constituída por dez questões fechadas em relação à satisfação consigo, com suas qualidades e capacidades, com 0 próprio valor, orgulho e respeito por si mesmo, atitude positiva em relação da si, sentimento de inutilidade e sensação de fracasso. Conta com as seguintes opções de resposta: concordo totalmente, concordo, discordo e discordo totalmente, em que cada item de resposta varia de 1 a 4 pontos.

A escala de auto-estima ${ }^{12}$, muito usada internacionalmente, obtevealto coeficientede confiabilidade (92\%) nos Estados Unidos. Para o Brasil, foi feita uma adaptação transcultural e validação por Avanci et al. ${ }^{20}$.

\section{Abordagem qualitativa}

Avaliamos as ações desenvolvidas ao longo da intervenção usando quatro instrumentos: 1) um questionário aberto em que cada policial registrou suas impressões sobre cada encontro (sendo 453 questionários ao todo); 2) um questionário aberto em que o policial imprimiu sua visão geral sobre a sensibilização vivencial no último encontro da intervenção (totalizando 46 questionários); 3) uma avaliação geral, no formato de grupo de debate, com um roteiro previamente estabelecido, também no último encontro (da qual participaram 46 policiais); e 4) um diário de campo sobre cada oficina, no qual foram registradas as impressões dos facilitadores/pesquisadores e dinamizadores/convidados.

\section{Análisedosdados}

Codificamos e processamos os questionários em um banco de dados no programa Epi Info, versão 6.0. A fim de minimizar os erros na fase de digitação eagilizar o processamento dos dados, cumprimos quatro etapas: codificação, digitação, corre ção e análise.

Para identificar erros, fizemos um sorteio aleatório de $10 \%$ dos questionários que foram revistos e conferidos. A penas um questionário apre sentou falha de digitação, assegurando boa qualidade dos dados.

Para análise das informações, importamos os bancos de dados para o software SPSS, versão 13.0, no qual realizamos a descrição das freqüências simples, o cruzamento de variáveis e os testes estatísticos para verificação das significâncias.

Todas as análises foram feitas segundo a característica dos grupos (experimental e controle) e a fase da investigação (antes e após a intervenção). 
Consideramos como diferenças estatisticamentesignificativas apenas aquelas menoresque $5 \%(p<0,05)$.

Utilizamos o teste de qui-quadrado de Pearson para a verificação de diferenças e, quando os pressupostos desse teste foram violados, utilizamos as tabelas de contingência $2 \times \mathrm{t}$. Para encontrar as diferenças estatisticamente significativas nas variáveis quantitativas e qualitativas ordinais, utilizamos o teste t, técnica empregada para comparar duas médias amostrais e verificar se elas são estatisticamente diferentes ${ }^{21}$.

M edimos a auto-estima através da média ponderada das respostas. Quanto maior o escore, maior o "nível" da auto-estima. Calculamos os tercis e construímos uma classificação de três "níveis" considerando até o primeiro tercil, baixa auto-estima, entre 0 primeiro e o segundo tercis, média autoestima e acima do segundo tercil, alta auto-estima. Realizamos também análise de fatores dos itens da escala com as respectivas cargas. Geramos duas estruturas de fatores, utilizando a rotação ortogonal de eixos varimax normalizada, com grau de explicação de 59\% da variância. No primeiro fator, concentraram-se itens da avaliação predominantemente negativa de si mesmo e, no segundo, a avaliação foi totalmente positiva.

A avaliação feita a partir da abordagem qualitativa se deu em duas etapas: na primeira, foi feita uma avaliação de cada oficina, por meio de um questionário aberto aos policiais após a ação; uma avaliação dos pesquisadores-dinamizadores; etudo foi sistematizado em um diário de campo, em cada oficina. Na segunda etapa, houve uma avaliação do processo de sensibilização como um todo, o que aconteceu por meio de um questionário aplicado aos policiais no último dia de encontro e também por meio de um grupo de discussão. N esse grupo, focamos a avaliação de todo o processo.

Os dados qualitativos foram construídos por meio da triangulação entre os informantes, os policiais submetidos à intervenção e os pesquisadores. Realizamos o processamento e a interpretação dos dados a partir do enfoque da análise temática em sua versão adaptada por M inayo ${ }^{16}$.

Realizamos uma leitura flutuante eintensiva de todo o material, organizando-o, depois em mapas, alocando em um mesmo arquivo todos os relatos pertinentes a cada temática. Identificamos e confrontamos os núcleos de sentido e suas autorias (se provenientes dos policiais ou dos pesquisadores).

A pesquisa foi aprovada pelo Comitê de Ética da Escola Nacional de Saúde Publica/Fiocruz e todos os participantes assinaram consentimento livreeesclarecido nos termos que recomenda a Resolução nº 196/96 de pesquisas com seres humanos.

\section{Resultadosediscussão}

\section{Avaliação da auto-estima}

A Tabela 1 mostra as médias da escala de autoestima para os grupos experimental e controle nas fases 1 e 2 da pesquisa. I dentificamos diferença es-

Tabela 1. M édias da escala de auto-Estima para os grupos Experimental e Controle nas fases 1 e 2 da pesquisa.

\begin{tabular}{|c|c|c|c|c|}
\hline \multirow[t]{2}{*}{ Itens da escala } & \multicolumn{4}{|c|}{ Grupose Fases } \\
\hline & GE Fase 1 & GE Fase 2 & GC Fase 1 & GC Fase 2 \\
\hline No conjunto, estou satisfeito comigo & 3,06 & 3,18 & 3,10 & 3,14 \\
\hline Às vezes, eu acho que não presto para nada & 3,45 & 3,48 & 3,33 & 3,38 \\
\hline Eu sinto que eu tenho várias boas qualidades & 3,50 & 3,53 & 3,48 & 3,46 \\
\hline $\begin{array}{l}\text { Eu sou capaz de fazer coisas tão bem quanto a maioria } \\
\text { das pessoas }\end{array}$ & 3,48 & 3,63 & 3,51 & 3,46 \\
\hline Eu sinto que não tenho muito do que me orgulhar & 3,29 & 3,35 & 3,16 & 3,45 \\
\hline Eu com certeza me sinto inútil, às vezes & 3,29 & 3,37 & 3,31 & 3,49 \\
\hline $\begin{array}{l}\text { Eu sinto que sou uma pessoa de valor, pelo menos do } \\
\text { mesmo nível que as outras pessoas }\end{array}$ & 3,40 & 3,51 & 3,42 & 3,41 \\
\hline Eu gostaria de poder ter mais respeito por mim mesmo & 3,09 & 3,06 & 2,98 & 3,23 \\
\hline No geral, estou inclinado a achar que sou um fracasso & 3,64 & 3,58 & 3,53 & 3,65 \\
\hline $\begin{array}{l}\text { Eu tenho uma atitude positiva com relação a mim } \\
\text { mesmo }\end{array}$ & 3,36 & 3,52 & 3,42 & 3,40 \\
\hline
\end{tabular}


tatística na auto-estima do GE da fase 1 (antes) para a fase 2 (após intervenção), com p=0,028.

Esta temática foi enfocada em $60 \%$ das atividades das oficinas da sensibilização vivencial, conforme mostra o Quadro 1. Nas oficinas "I ntegrando para resgatar sonhos", "Relaxando para agüentar o tranco", "Polícia e vida familiar", "Auto-imagem do policial", "O ficina de crescimento pessoal" e na peça teatral "Navegar é preciso", a auto-estima foi um aspecto bastante privilegiado.

$\mathrm{N}$ ão foi observada nenhuma mudança significativa da fase 1 para a fase 2 no GC, demonstrando que a auto-estima desse grupo permaneceu similar após os seis meses de atividades realizadas no treinamento proposto pelo Grupo Executivo do Programa Delegacia Legal.

Quando comparamos o GE com o Grupo de Controle na fase 1 , encontramos que eles eram similaresantes da intervenção no quese refereà autoestima. Entretanto, embora o GE tenha se modificado na fase 2, ele não se diferenciou estatisticamente do Grupo de Controle após a sensibilização. Este dado dá margem a algumas suposições. A primeira delas é que a perda de pessoas no GE (por transferência para outra unidade) pode ter minimizado o efeito da interven ção, di minuindo 0 tamanho da amostra (o GE começou com 76 participantes e terminou com 49; e o Grupo de Controle começou com 71 efindou com 69). A segunda hipótese éque os seis meses de intervenção podem não ter sido suficientes para provocar um efeito com tamanha intensidade.

A abordagem qualitativa do estudo possibilitou um olhar mais sensível eamplo quanto à questão da auto-estima, captando mudanças que não foram identificadas pelos instrumentos quantitativos. É o que revelam algumas falas dos policiais registradas durante a avaliação das oficinas, ao expressarem que estas trouxeram "a certeza de que podemos ser diferentes". Ou ainda, a que revelou que tal intervenção possibilitou "pensar que ainda somos importantes, apesar do massacre a que estamos submetidos". O utra fal a que chamou a atenção dos pesquisadores foi a que revelou o sentimento e 0 autoconceito de um dos policiais, ao desabafar que "antes de sermos policiais, somos gente. Gente que sofre, se angustia, erra e aprende".

No Brasil, há poucos estudos que empregaram a escala de Rosemberg para aferir auto-estima, dentre os quais a investigação de Souza e Ferreira ${ }^{22}$ com mães enão-mães, cujo objetivo foi analisar as implicações da condição de maternidade e de não-maternidade para a construção da autoestima pessoal e coletiva das mulheres, e a experiência de Assis e Avanci ${ }^{20}$, com mais de 2.000 adolescentes da região de São Gonçalo, no Rio de Janeiro. No entanto, estes estudos abordam grupos distintos dos policiais desta pesquisa, dificultando comparações. Contudo, consideramos importante registrar que as médias encontradas por Souza e Ferreira são semelhantes às dos policiais.

Avaliação da qualidade de vida

Os dados relativos à avaliação da qualidade de vida dos policiais podem ser observados na Tabela 2. N ela, vemos que em ambos os grupos as menores médias se referem ao domínio do meio ambientee que o domínio das relações sociais apresenta as maiores médias. Também percebemos que as médias do GE são bem semelhantes às do Grupo de Controle e que ambos apresentaram médias maiores na fase 2 .

No entanto, a avaliação mostrou que no GE não houve mudança estatisticamente significativa da qualidade de vida em nenhum dos domínios pesquisados, quando comparamos a fase $1 \mathrm{com}$ a fase 2 da pesquisa.

Complementando os achados da aferição quantitativa, a análise qualitativa demonstrou resulta-

Tabela 2. M édias dos grupos experimental e controle nas fases 1 e 2, segundo domínios do WHOQ OL-Bref.

\begin{tabular}{lcccccccccc}
\hline \multicolumn{1}{c}{ Domínios } & \multicolumn{2}{c}{ GE Fase 1 } & \multicolumn{3}{c}{ GE Fase 2 } & \multicolumn{2}{c}{ GC Fase 1 } & \multicolumn{3}{c}{ GC Fase 2 } \\
\hline & M édia & D P & M édia & D P & p & Média & D P & M édia & D P & p \\
\hline Físico & 15,35 & 2,39 & 15,92 & 3,18 & 0,274 & 15,56 & 3,14 & 15,83 & 3,69 & 0,6309 \\
M eio Ambiente & 11,71 & 2,50 & 12,65 & 3,18 & 0,082 & 11,89 & 2,65 & 12,40 & 3,42 & 0,3263 \\
Relações sociais & 15,25 & 3,06 & 16,31 & 3,20 & 0,0631 & 16,22 & 3,13 & 16,29 & 3,98 & 0,9111 \\
Psicológico & 15,25 & 1,98 & 15,45 & 2,76 & 0,6264 & 15,73 & 2,92 & 15,93 & 2,99 & 0,6874 \\
\hline
\end{tabular}


dos positivos. A avaliação dos policiais sobre as oficinas destacou-as como uma "iniciativa inovadora", "diferente de tudo que tinham tido antes". Foram apontadas como importantes, tanto do ponto de vista da dinâmica familiar como para a qualidade de vida, pois criaram uma "possibilidade de refletir sobre a relação familiar", "fez pensar sobre as minhas ações com os meus filhos e esposa" e, ainda, "resgatar valores adormecidos". Também foram registradas expressões de sentimentos de leveza efelicidade: "me sinto mais leve, feliz, depois da palestra"; e de que "atividades como essa aumentam a vontade de viver!"

Pelos dados da Tabela 2, percebemos queno GE o domínio das relações sociais ( que contempla variáveis relativas às interações sociais e pessoais, suporte/apoio social e atividade sexual) e o domínio do meio ambiente (que abrange questões ligadas à segurança física e proteção, ambiente no lar, recursos financeiros, cuidados de saúde e sociais, oportunidades de adquirir novas informações e habilidades, recreação e lazer, ambiente físico e transporte) ficaram próximos da significância estatística.

No tocante ao domínio das relações sociais, este achado parece estar indicando um movimento de mudança no $\mathrm{GE}$, tendo em vista que as três primeiras variáveis abrangidas nesse domínio foram contempladas diretamente em al gumas oficinas (Quadro 1). Esta suposição também se apóia no fato de que os grupos eram diferentes neste domínio na fase 1 do estudo $(p=0,0571)$ eao final tornaram-se semel hantes graças ao incremento da média do GE, indicando um movimento de me Ihora das interações nesse grupo, embora tal mudança não tenha sido suficiente para ser aferida no nível de significância de $5 \%$ ( $p=0,0631)$. 0 mesmo não ocorreu com o Grupo de Controle, que permaneceu estável nesse domínio $(p=0,9111)$.

Não houve mudança significativa no domínio psicológico em nenhuma das análises realizadas (comparação dos grupos experimental e controle nos momentos antes e após a intervenção e comparação do GE com Grupo de Controle na fase $1 \mathrm{e}$ na fase 2). Este dado foi uma surpresa para os pesquisadores, uma vez que a escala de Rosemberg aponta para uma mudança significativa na auto-estima do GE na fase 2 comparada à fase 1 . Tal discrepância pode ser explicada pelo fato de que o domínio psicológico do WHOQOL-Bref, além da auto-estima, contempla outras variáveis, tais como memória, concentração, imagem corporal, aparência e sentimentos negativos, os quais não foram abordados diretamente nas oficinas.

Os resultados aqui encontrados não diferem muito dos observados em outros grupos específi- cos. 0 estudo realizado por Berlim et al. ${ }^{23} \mathrm{com}$ pacientes brasileiros com depressão profunda crônica mostra médias menores que as dos policiais do GE nos domínios físico e psicológico. No entanto, os pacientes com depressão apresentaram maiores médias que esses policiais no domínio das relações sociais; do mesmo modo, os deprimidos tinham maior média no domínio do meio ambiente antes da intervenção.

Outro estudo que também usou o WHOQOLBref foi realizado por Souza et al..$^{24}$ com uma amostra de conveniência de 72 idosos de uma comunidade de baixa renda da cidade do Rio de Janeiro. Os autores encontraram médias menores que as dos policiais nos domíniosfísico, psicológico edas relações sociais. Já no domínio meio ambiente, os policiais, na fase 1 apresentaram médias inferiores às dos idosos.

Outro estudo com idosos em Taiwan, elaborado por $\mathrm{H}$ wang et al. ${ }^{25}$, demonstrou que, em relação a esse grupo, os policiais tiveram médias superiores nos domínios físico, psicológico e das relações sociais, mas foram superados pelos idosos de Taiwan no domínio meio ambiente.

Berlim et al..$^{23}$ acompanharam uma amostra brasileira de pacientes com depressão crônica profunda, durante um período de doze meses. Obtiveram médias inferiores às dos policiais nos domínios físico e psicológico. Já nos domínios relações sociais e meio ambiente, as médias dos pacientes foram superiores às observadas no presente estudo, excetuando-se a do GE na fase 2 .

Para efeito de comparação, na Tabela 3 mostramos as médias dos estudos supracitados, bem como as médias referentes aos policiais civis aqui investigados.

Existe uma escassez de pesquisas com policiais e isto leva-nos a comparar os dados da presente pesquisa com estudos que envolveram grupos distintos em termos etários, socioeconômicos e culturais. Embora não seja possível nos debruçar sobre estas diferenças no espaço deste artigo, é importante chamar a atenção para alguns dos achados. Os policiais civis encontram-se com melhor qualidade de vida no que se refere aos domínios físico e psicológico do que os grupos de idosos e pacientes deprimidos estudados, conforme seria 0 esperado. No entanto, é surpreendente que esses agentes da segurança apresentem-se em piores condições do que alguns desses grupos (idosos de comunidade de baixa renda e pacientes deprimidos) no tocante aos domínios das relações sociais e do seu ambiente. Estes dados refletem, por um lado, as dificuldades que têm nos relacionamentos interpessoais, tanto no desempenho das atividades 
Tabela 3. M édias do WHO Q OL-Bref em vários estudos nacionais e internacionais.

\begin{tabular}{|c|c|c|c|c|c|}
\hline Estudos & & $\begin{array}{l}\text { Domínio } \\
\text { Físico }\end{array}$ & $\begin{array}{c}\text { Domínio } \\
\text { Psicológico }\end{array}$ & $\begin{array}{c}\text { Domínio } \\
\text { Relações Sociais }\end{array}$ & $\begin{array}{c}\text { Domínio M eio } \\
\text { Ambiente }\end{array}$ \\
\hline Souza et al. ${ }^{24}$ & M édia & 12,85 & 14,05 & 14,02 & 11,80 \\
\hline $\mathrm{H}$ wang et al. ${ }^{25}$ & Média & 13,00 & 13,00 & 13,00 & 13,00 \\
\hline Berlim et al..$^{23}$ & M édia & $\begin{array}{cc}1 & 2 \\
13,38 & 11,44\end{array}$ & $\begin{array}{cc}1 & 2 \\
13,61 & 12,53\end{array}$ & $\begin{array}{cc}1 & 2 \\
19,19 & 18,05\end{array}$ & $\begin{array}{cc}1 & 2 \\
13,97 & 12,47\end{array}$ \\
\hline
\end{tabular}

laborais quanto no âmbito privado, conforme já identificado em outros estudos ${ }^{1,5}$. Por outro lado, as comparações expressam também as dificuldades diante das adversidades da realidade carioca degrandeegraveviolência, que os obriga a enfrentar pessoas e ambientes perigosos.

Essas conclusões corroboram estudo de H siuChao et al. ${ }^{26}$, queusaram o questionário SF-12 (12Item Short-Form H ealth Survey), medindo qualidade devida edepressão em 832 policiais dacidade de Kaohsiung, Taiwan. Os autores demonstraram que 0 estresse provocado pelas particularidades do trabalho policial pode resultar em depressão, comprometendo assim sua qualidade de vida. Verificaram que $21,6 \%$ da amostra apresentavam um nível de depressão importante e que os policiais acima de 50 anos de idade tiveram escores bastante significativos nos aspectos subjetivos da qualidade de vida.

\section{Avaliação da intervenção}

Foram muitos os aspectos favoráveis da intervenção. Dentre eles, o fato da proposta ter desviado o foco do trabalho policial para a pessoa do policial. Esse foi um ponto sinalizado e valorizado por eles próprios.

A maior integração da equipe também foi ressaltada como um ponto positivo da ação. A percepção dos pesquisadores coaduna com essa visão. No diário de campo da equipe, encontram-se registros da gradativa integração dos participantes no decorrer do processo. No grupo de discussão para avaliação do programa, novamente essa questão étrazi da: lamentam o término e registram a cumplicidade que passou a existir nesse grupo devido aos encontros quinzenais que a equipe passou a ter fora da delegacia: "a gente nunca tinha rido juntos".

As ações de humor/lazer e aquelas que conseguiram dinamizar o grupo foram as mais bem avaliadas. Claramente as atividades que se propuseram à descontração, relaxamento e diversão que braram o que Bretas ${ }^{27}$ chama de "mais do mesmo". Trouxeram elementos novos ao cotidiano policial, provocando surpresa eentusiasmo. A avaliação positiva, por parte da maioria deles, fica nítida nos agradecimentos encontrados em muitos questionários: "o fato de ter um seguimento da sociedade preocupada com o bem-estar policial já foi extremamente valioso". São muitas as falas que expressam o sentimento de valorização por terem feito parte da intervenção.

Poucos foram os pontos fracos sinalizados pelospoliciais. M ereceram críticas a precariedadedos recursos audiovisuais e o espaço inapropriado para algumas atividades. Foram considerados negativos ainda alguns temas abordados e a forma de conduzi-los por alguns palestrantes. Ficou clara a valorização dos profissionais que possuem perfil interativo, dinamizador e com conhecimento da realidade policial. Desconhecendo o que foi feito no processo de construção da proposta, muitos sugeriram que, para um próximo curso, se faça uma pesquisa sobre quais temas os policiais gostariam de discutir.

Alguns policiais sinalizaram a obrigatoriedade da presença (exigida pela disciplina da corporação) como um fator negativo, embora houvesse visão contraditória em relação esse ponto: "precisa ser obrigatório sim, voluntariamente acho que eles não fariam e perderiam essa oportunidade, alegariam que não têm tempo".

Perguntamos aos policiais em que a sensibilização contribuiu para a sua vida profissional e pessoal; se percebiam al guma diferença entre essas atividades e outras que tivessem participado na polícia; pontos fortes e fracos da ação e comentários sobre toda a intervenção. A avaliação de $78 \%$ deles foi dequea intervenção contribuiu tanto para a vida pessoal quanto profissional. 0 aprendizado em lidar com as adversidades, a integração da equi- 
pe, a possibilidade de reflexão sobrea qualidade de vida no âmbito pessoal e profissional e a minimização do estresse (pelo relaxamento e humor) foram as contribuições que mereceram mais menções. Entretanto, 20\% registraram que as ações pouco ou nada contribuíram para suas vidas.

Por fim, muitos sugeriram que tais atividades deveriam fazer parte do calendário de formação e que "deveriam continuá-las no próprio ambiente de trabalho". Lamentam o pequeno impacto que a intervenção terá, por envolver um número ínfimo depoliciais secomparado ao conjunto deles, desejando que ações como essas sejam estendidas a todos.

\section{Conclusões}

Os resultados aqui obtidos demonstram queépossível construir uma metodologia de intervenção visando ao suporte emocional para policiais civis, respeitando-se seu direito à saúde mental. Essa certeza se soma a iniciativas que vêm ocorrendo em várias partes do mundo. Por exemplo, em Londres, está sendo realizado, desdeo ano de 2003, o Quality of Working Life, com objetivo de avaliar causas e desenvolver estratégias de combateao estresse, buscando maior equilíbrio no trabalho do policial ${ }^{28}$. $\mathrm{Na}$ capital comercial da Índia, Bombaim, também está sendo realizado um projeto para terapia antiestresse para policiais. 0 foco do projeto é o desenvolvimento da concentração a partir de técnicas de relaxamento ${ }^{29}$. N a cidadede Ruston, Louisiana, está sendo desenvolvido um treinamento voltado para o desenvolvimento de atitudes pós-situações críticas, a favor dos policiais ${ }^{30}$.

No entanto, são ainda raros os estudos da área da segurança pública que focalizam o profissional policial. M ais raras ainda são as propostas de intervenção controladas por avaliação. Daí a importância de um estudo como o aqui realizado. Localizamos na literatura internacional apenas uma experiência de intervenção controlada por avalia- ção, semel hante à que realizamos, com 116 policiais da República da Eslovênia, num programa denominado Antistress Program for Police O fficers. A proposta constituída por várias oficinas com temáticas diversas visava à diminuição do estresse e mel hor qualidade de vida dos policiais ${ }^{4}$. $\mathrm{Na}$ avaliação da intervenção, os autores verificaram que os policiais recomendavam positivamente o programa a seus colegas por causa do conteúdo, de sua implementação prática e da sua eficácia na redução do nível de estresse.

Um dos traços marcantes das pesquisas como a descrita neste artigo é oferecer a rara oportunidade de escuta e de voz para esses homens e muIheres. Essa escuta constitui a base de intervenções que visem ao aprimoramento da saúde desses trabalhadores que desempenham atividades insalubres e arriscadas no seu cotidiano e quase não dispõem de alternativas para realizar a catarse do estresse que tais atividades geram.

Negligenciar as carências de suporte emocional dos policiais tem sido a tônica dos gestores da Polícia ao longo dos anos. Com raras exceções, como o SI SM EN (Sistema de Saúde M ental da Polícia M ilitar do Estado de São Paulo), a experiência de Bourguignon ${ }^{31}$ no Espírito Santo e o Programa Delegacia Legal no Estado do Rio de Janeiro (durante um tempo determinado), as iniciativas têm focalizado apenas as necessidades de aprimoramento e treinamento técnico.

A motivação deste trabal ho nasceu da convicção de que os desafios na área da segurança pública não são exclusivamente do governo, mas sim de toda sociedade. Balestreli ${ }^{32}$, um grande estudioso da problemática dos direitos humanos no Brasil, afirma que os policiais podem ser, quando atendidos em suas próprias necessidades, uma das maiores forças de implementação dos direitos humanos no país. Para que isso ocorra, é necessário investimento no processo educacional das polícias, estimulando, incentivando e produzindo conhecimentos que possam ajudá-los a se tornar pessoas melhores no desenvolvimento de sua práxis. 


\section{Referências}

1. M inayo MCS, Souza ER, organizadores. Missão investigar: entre 0 ideal a realidade de ser policial. Rio de Janeiro: Garamond; 2003.

2. M inayo M CS, Souza ER, Assis CP, Gomes R, M angas RM N, Schenker M, Cavalcanti M LT, Barros FAC, Correa FAP. Relatório do estudo comparativo entre policiais civis e militares do Rio de Janeiro sobre riscos pessoais e profissionais. Rio de Janeiro: Centro Latino Americano de Estudos de Violência e Saúde/ENSP/ Fiocruz; 2006.

3. M inayo-Gomez C, Thedim-Costa SM . A construção do campo da saúde do trabalhador: percurso e dilemas. Cad Saúde Pública 1997; 13(supl 2):2-10.

4. Visnikar H, Mesko G. Evaluation of The Art of Living Basic Course as the Anti-stress Program for police Officers in the Slovenian Police. Republic of Slovenia: M inistry for Internal Affairs; 2002.

5. Dejours C. A loucura do trabalho: estudos de psicopatologia do trabalho. São Paulo: Cortez- Oporé; 1992.

6. Constantino P. Riscos vividos e percebidos por Policiais Civis do M unicípio de Campos dos Goytacazes [tese]. Rio de Janeiro (RJ): Escola Nacional de Saúde Pública/Fiocruz; 2006.

7. Laurell $A C$, Noriega M. Processo de produção e saúde. São Paulo: Hucitec;1989.

8. The WHOQOL Group. The World Health Organization quality o life. Assessment (WHOQOL): position paper from the World Health Organization. Social Science and M edicine 1995; 41(10):1403-1409.

9. M inayo M CS, Hartz ZMA, Buss PM. Qualidade de vida e saúde: um debate necessário. Cien Saude Colet 2000; 5(1):7-32.

10. Branden N. Auto-estima e os seus pilares. São Paulo: Saraiva; 1995.

11. Branden N. Auto-estima: como aprender a gostar de si mesmo. São Paulo: Saraiva; 2000.

12. Rosenberg M. Society and the adolescent self-image. Princeton University Press, Princeton; 1965.

13. Bednar RL, Peterson SR. Self-esteem: paradoxes and innovation in clinical theory and practice. Washington, D.C.: American Psychological Association; 1995.

14. Coopersmith S. Coopersmith Self-esteem Inventory. Palo Alto: Consulting Psychologists Press; 1989.

15. Assis SG, Avanci JQ. Labirinto de espelhos: formação da auto-estima na infância e na adolescência. Rio de Janeiro: Fiocruz; 2004.

16. M inayo M CS. 0 desafio do conhecimento: pesquisa qualitativa em saúde. 8a ed. São Paulo: Hucitec; 2006.

17. Thiollent M. Crítica metodológica, investigação social. São Paulo: Polis; 1987.

18. Cohen E, Franco R. Avaliação de projetos sociais. Rio de Janeiro: Vozes; 1993.

19. Fleck MPA. 0 instrumento de avaliação de qualidade de vida abreviado da Organização Mundial da Saude (WHOQOL-100): características e perspectivas. Cien Saude Colet 2000; 5(1):33-38.
20. Avanci JQ, Assis SG, Santos NC, Oliveira RVC. Adaptação transcultural de escala de auto-estima para adolescentes. Psicologia Reflexão e Crítica 2007; 20(3):397405.

21. Larson HJ. Introduction to Probability Theory and Statistical Inference. New York: John Wiley \& Sons; 1982.

22. Souza DB, Ferreira MC. Auto-estima pessoal e coletiva em mães e não-mães. Estudos de Psicologia 2005; 10(1):26-39.

23. Berlim MT, Pavanello DP, Caldieraro M, Fleck PA. Reliability and validity of the WHOQOL BREF in a sample of Brazilian outpatients with major depression. Qual Life Res 2005; 14:561-564.

24. Souza ER, Ribeiro AP, Atie S, Souza AC. Estado de direito e a violência contra o idoso. Rio de Janeiro: Centro Latino Americano de Estudos de Violência e Saúde Jorge Careli/Fiocruz; 2006.

25. H wang $H F$, Liang WM, Chiu $Y N$, Lin MR. Suitability of the WHOQOUL-BREF for community-dwelling older people in Taiwan. Age and Ageing 2003; 90(4):165-170.

26. Hsiu-Chao C, Chou F, Chen MC, Su SF, Wang SY, Feng WW. et al. A Survey of Quality of Life and Depression for Police officers in Kaohsiung, Taiwan. Quality of Life Research 2006; 15(5): 925-932.

27. Bretas ML. Observações sobre a falência dos modelos policiais. Tempo Social- Rev. Sociol. USP 1997; 9(1):79-94.

28. Cooper $C$. Anti-stress scheme boosts health and morale of city of London police: Wellbeing. Personnel Today [periódico na Internet] 2006 [acessado 2006 jun 05]. Disponível em: http://www.personneltoday. com/articles/articles.aspx?liarticlel $D=34257 \&$ printerfrie

29. Ahmed Z. Indian police learn to de-stress. Story From BBC N ews [periódico na Internet] 2006 [acessado 2006 jun 04]. Disponível em: http://news.bbc.co.uk/go/pr/ fr/-/2/hi/south_asia/2982707.stm

30. Brown C. Area Officers Receive Critical Incident Training. Gulf States Regional Center For Public Safety Innovations [site na Internet] 2006 [acessado 2006 jun 04]. Disponível em: http://GulfStatesRegionalCenterforPublicSafetyl nnovations

31. Bourguignon DR, Borges LH. Análise das condições de trabalho e saúde dos trabalhadores da Polícia Civil no Espírito Santo. Revista Brasileira de Saúde Ocupacional 1998; 24(91/92): 95-113.

32. Balestreli R. Direitos Humanos: Coisa de Polícia. [site na Internet] 2006 [acessado 2006 mar 08]. Disponível em: http://www.torturanuncamais.org.br/mtnm_pub/ pub_livros/rb_ciosa_policia/livro_coisa_po_index.ht

Artigo apresentado em 18/09/2006

A provado em 22/09/2006

Versão final apresentada em 27/09/2006 